Helen Resneck-Sannes

\title{
Bioenergetics: Past Present and Future
}

International Institute for

Bioenergetic Analysis

2005 (15)
Bioenergetic Analysis

15. Volume, No. 1, 2005, Page 33-54

Psychosozial-Verlag

DOI: 10.30820/0743-4804-2005-15-33 
Bibliographic information of Die Deutsche Nationalbibliothek (The German Library) The Deutsche Nationalbibliothek lists this publication in the Deutsche Nationalbibliografie; detailed bibliographic data are available at http://dnb.d-nb.de.

2005 Psychosozial-Verlag GmbH \& Co. KG, Gießen, Germany

info@psychosozial-verlag.de

www.psychosozial-verlag.de

\section{(C) $(1) \Theta \Theta$}

This work is licensed under the Creative Commons Attribution-NonCommercialNoDerivatives 4.0 International License (CC BY-NC-ND 4.0). This license allows private use and unmodified distribution, but prohibits editing and commercial use (further information can be found at: https://creativecommons.org/licenses/by-nc-nd/4.0/). The terms of the Creative Commons licence only apply to the original material. The reuse of material from other sources (marked with a reference) such as charts, illustrations, photos and text extracts may require further permission for use from the respective copyrights holder.

Cover layout: Christof Röhl

Editorial staff: Kristine Klein

Layout: Katharina Appel

https://doi.org/10.30820/0743-4804-2005-15

ISBN (PDF-E-Book) 9978-3-8379-6805-7

ISBN (Print) 978-3-89806-395-1

ISSN (Online) 2747-8882 · ISSN (Print) 0743-4804 


\title{
Bioenergetics: Past, Present and Future
}

\author{
Helen Resneck-Sannes
}

Several people helped me with this speech and I want to acknowledge them. Thank you to Michael and Sylvia Conant and to Virginia and Bob Hilton for helping me to organize the speech as well as clarify certain concepts. I also want to thank my husband, David and daughter, Myrrhia for their love, support and intelligence and a special thank you to Myrrhia for her writing skills. It is with deep appreciation I thank my primary Bioenergetic trainers, David Finlay and Eleanor Greenlee. Without their commitment to their own process as well as to Bioenergetics and the Institute, I would not be here. Finally, I want to thank Jim Miller. From my first time at Whistler, he encouraged me to become a trainer and a teacher. I still miss him a great deal.

And then ... the people of Brazil. What can I say? At conferences over the years I would hear the Brazilians dancing and singing until late in the evening. At first I was resentful, and then I realized that I was jealous. I wanted to be having that much fun. Every year when asked where we should have the next conference, I would write, Brazil. I have been waiting for this conference for years and it is a real pleasure to be here.

The literature I discuss has all been written in English because that is the only language I feel adequate to read with real understanding. I will also cover some of the same material as Bob Lewis. I admire his ability to so beautifully describe empathic attunement as it is experienced in the soma/psyche of the therapist.

Morris asks his son, now aged 10, if he knows about the birds and the bees. »I don't want to know «, the child said, bursting into tears.

Confused, the father asked his son what was wrong.

»Oh Dad «, he sobbed, »at age six I got the sthere's no Santa< speech. At age seven I got the sthere's no Easter bunny speech. If you're going to tell me now that grown-ups really have sex, I've got nothing left to live for! « 
I thought I would have your attention if I mentioned the word sex; and to put you at ease, I'm not going to announce that the future of Bioenergetics shouldn't still have sex as an important aspect of the therapy. In 12 step programs for addictions, people stand up and tell their truth. They say things like: » My name is ... and I'm an alcoholic, sex addict, cocaine abuser ...", whatever. Well, I'm going to stand up here in front of you all today and tell the truth. »My name is Helen Resneck-Sannes and I entered Bioenergetic Analysis to have `The Big $\mathrm{O}$ « . You know, the full bodied orgasm from head to toe, from the inside out; that orgasm described in the book, For Whom The Bell Tolls, that causes the earth to move off its axis.

When I began my Bioenergetic therapy, I was having good sex with my husband, regular orgasms, but Lowen and Reich were describing something quite powerful. At the time I was confused about how this incredible orgasm occurred without a partner; and only later came to understand that the orgasmic reflex was an energy wave that circulated throughout the body, creating a harmonious rhythm that was quite separate from sexual intercourse. Well, I think I've had >The Big O < a couple of times; if not $>$ The Big $\mathrm{O}<$, I definitely experienced streamings that coursed through my entire body producing a harmonic vibratory sensation. However, in 1984 or 1985 during a talk in Berkeley, California, Lowen admitted that he was 74 years old and had never had >The Big $\mathrm{O}$ < and doubted that he ever would, as he was getting older. Although he wished for a complete orgasm reflex, he had become aware that harmonic streamings on the mat does not necessarily indicate a healthy person or even a healthy sexual relationship.

Although I'm beginning the talk with a personal story, I think my involvement with Bioenergetics mirrors the development of it as a theory and practice. The reality is that Bioenergetics is a therapy being created in our offices, in our training programs, in our writings, and at these conferences. And we have a new curriculum thanks to the commitment, tenacity, and good will of our faculty and especially to the writers Guy Tonella and Violaine De Clerck.

As I see it, three major paradigms emerged over time and influenced the members of the Bioenergetic community and their practice of therapy. The first paradigm in Bioenergetics as developed by John Pierrakkos and Alexander Lowen viewed the person from the outside. Open the armor 
and the person would be free. When I began therapy, I had some concept of what a Bioenergetic Analysis might look like. It quickly changed. During the first few sessions, my therapist read my body and taught me how to ground. After that, every session began with me in a squatting position up against the wall. We both hoped that my legs would tire, that I would give in and allow softer feelings to emerge. By giving up control, supposedly, the armor around my chest would open; and subsequently, my heart. I didn't realize at the time the profound effect such an experience would have on me. As my friends saw me become more open with my emotions and willing to expose my vulnerability, they also enrolled in Bioenergetic therapy.

As the practice of Bioenergetics developed, a second paradigm emerged. Influenced by the teachings of Stanley Keleman, David Boadella, Gerda Boyenson, Peter Levine and others, the focus shifted. My therapist was having sessions with Stanley Keleman and being trained by Gerda Boyenson; and because of their influence, my therapy changed. Now, she not only commented about my outside structure, she also focused on the flow of the energy inside my body. So after my legs were tired from being against the wall, I lay on the mat while she with her hands, gave support to my head or my belly, hoping to soften the sinner tube<, the flow of energy from my throat through my viscera. It was during that time that my therapy stalemated and ended. I became aware that to open my heart, I needed an empathic attuned person who could resonate with me and feel what I needed somatically, emotionally and verbally.

And one morning at a conference in Montebello, I was finally able to voice my protest about being viewed as an energetic body detached from a person. My friend was practicing a technique she had learned from Peter Levine. In case you are unfamiliar with him, he spoke at our conference in Montebello a few years ago and has developed a somatic therapy for working with trauma. The technique is called: >Opening the Four Diaphragms . I like this intervention; and in fact, taught it to the faculty earlier this week. When working together in the past, she had noticed that my body sometimes was able to go into what Levine calls harmonic resonance or the streamings that comprise `The Big O $<$. As she became more intent on watching my body, I wondered if she really cared about me or was more attached to producing a somatic effect. I began to cry and said 
to her: »Please be as interested in me as you are in my body. "She, being a sensitive therapist reached and took my hand. Later that morning Bob Lewis was addressing the entire conference at Montebello. He mentioned that he had said the same thing to his therapist: »Please be as interested in me as you are in my body ". Thanks again Bob Lewis.

At this time a third paradigm is emerging influenced by the teachings and writings of Len Carlino, David Finlay, Bob Hilton, and Bob Lewis and supported by the latest neurobiological research and investigative studies regarding the process and efficacy of psychotherapy. Research on what causes change in psychotherapy has repeatedly given us the same finding, that therapy change is occurring because of something happening in the relationship between the therapist and client. No longer is the therapist a separate objective observer reading the outside of the body or a neutral person affecting the inside.

Angela Klopstech (2002) extends Stark's (1999) model of three ways of interacting with clients and demonstrates how a body intervention can be used in these different ways. In case you are unfamiliar with Martha Stark's work, she spoke at the conference in Montebello 2001. Klopstech describes classical Bioenergetics as basically a » one person psychology «, with the therapist functioning as an observer, who interprets and provides knowledge to the client. In her words: »Over the last decade, Bioenergetic Analysis experienced a process similar to psychoanalysis, i.e., a shift towards a more relationship-oriented approach (...). This process is still much more in its infancy as compared to the shift that psychoanalysis has undergone. The relevant Bioenergetic literature is borrowing mainly from psychoanalytic publications on an sas needed basis and has not yet jelled into a coherent theoretical structure (Klopstech 2002, p. 58). She describes working with a client who has difficulty expressing his anger to his wife, by using a typical Bioenergetic technique, hitting the cube. First, she provides a classical Bioenergetic experience, interpreting and providing knowledge to the client. Her second intervention provides an empathic curative experience, while during her third intervention, she engages in an active relational interchange.

To understand the development of these three paradigms, we must trace the history of Bioenergetics as a therapy. When discussing our theoretical roots, we begin with Reich. His theories and research included not only the domains of psychotherapy but extended beyond into the realms 
of energy, politics, and the weather. He was a psychoanalyst and was formulating his psychotherapy of the body and energy as a reaction against the tyranny of mentalization and words. When he focused on patterns in patients' actions, thoughts, feelings, and relationships, he was observing how they correlated with the person's body in terms of their muscular holdings and life energy. Patients' past experiences - their early attachments, childhood experiences and historical relationships - were important for understanding character. Character is the way the person relates in the present. Because he was more interested in how the patient was in the therapeutic hour and paid less attention to his patients' associations and thoughts, Reich might be described as one of the first relational psychotherapists.

Lowen picked up on Reich's middle period when he was interested in correlating psychoanalytic theory and the body. Like Reich, he was formulating his theories in reaction against the bias of verbalization, and tended to de-emphasize mental states, images, and dreams. He made some brilliant contributions to the field of psychotherapy. His classic work, The Language of The Body (1958) defines a character analysis in relationship to a developing body. In addition, he describes what psychological stresses, and manifestations occur, when one is living in a society providing an immense amount of stimulation at a rapid pace and judges its standard as something outside of the person's internal feelings and sense of themselves. Within the field of psychoanalysis his book on narcissism places it as a process occurring within and among all characters. This is a brilliant piece of analysis formed at least in large part by the way I think Lowen often knows his truth, not by analyzing theories, but by observing, being with and resonating to people.

And a year and a half ago at Pawling, I was about to take a walk, when Lowen called me into the room and began to talk about what he felt had been important to him in his therapy journey. He said to stay true to what you know; and for him, that has been to follow the body. He said that he had been briefly interested in Reich's concept of orgone and energy, but now he saw that as a distraction to what was truly important.

Reich and Lowen are our legacy, the roots from which we grow. What has Bioenergetics become today and how does it compare to other therapeutic 
modalities? An area of controversy emerging in the therapeutic literature is the role of affect and emotion. I think it is safe to say that most Bioenergetic therapists work with affect and emotional expression. When opening up somatic holding patterns, which are blocks to emotional needs, we certainly support people in their emotional expression. When we say, we help the person be with their feelings, I'm not referring to sgetting rid of feelings $<$ I remember at a talk in Greece a few years ago, Lowen stood up and yelled: »Bioenergetics is not catharsis «. Catharsis is the discharge of feelings. In a character analysis certain feelings are encouraged, while at other times, affects are contained and soothed.

The role of emotions and affect are being reexamined in attachment and trauma theory. Cognitive behavioral therapists and trauma therapists work to contain and modulate affect, while therapists working in the realm of emotionally focused psychotherapy, psychoanalytic, and Bioenergetic Analysis believe that change occurs when affect is fairly high. One of the latest concepts in the field of psychotherapy comes from the literature on trauma and is used to describe the processes when patients are managing highly charged emotional and traumatic material. This is the therapeutic window. It is the optimal level of arousal and affect for processing traumatic material. I'll say it again. The therapeutic window is the optimal level of arousal and affect for processing traumatic material. When discussing this concept, I will be using a few terms from neurobiology. You don't need to remember them to understand the concepts.

In neurobiological research, a dichotomy between the two areas of the brain is emphasized. The limbic brain and the cortical brain are distinct in function as well as anatomical location (cortical on top of the limbic). How these two areas of the brain interact with each other varies not only between individuals, but from minute to minute within an individual. The limbic system corresponds to a phylogenetically older, unconscious, reflexive affective brain. This part of the brain processes somatosensory (external sensory material as well) non-verbal material. It is the emotional brain that develops between one to three years of life and is influenced by our early experiences with caretakers (other parts of the brain develop during this period as well. And: the emotional brain< keeps developing during a lifetime). It is the part of the brain that Bioenergetic Analysts, more than other psychotherapists work with directly (this is - to my knowledge - only 
a hypothesis so far; it has not been investigated so far. And besides: e.g. flooding techniques in behavior therapy probably stimulate limbic areas as well). Cortical areas, on the other hand, represent the narrative, linguistic, symbolic, and conscious brain, which is the area of primary focus in a cognitive and psychoanalytic therapy. There are connections between the two, and each can influence the other. These two areas of the brain process memory and information differently. Emotional memory of the limbic system is encoded by intense affective or sensory events such as trauma. Declarative memory is encoded in the symbolic form of language. It has been proposed by many, such as Brockman, Siegel (1999), and Schore (1997) that therapeutic change results from bringing the full capacities of the cortical brain to intense affective experiences. Basically, this has been the process of a Bioenergetic Analysis, to bring our bodily experiences into conscious awareness and full intellectual understanding. In the past we focused on the outside of the body, somatic holding patterns, and then the inside of the body and visceral feelings.

A second concept that is appearing in the literature is that bodily states are represented in the brain. Now is the time to focus on the body that lives in the mind or the body/mind. This term is an important concept. There has been a split in Bioenergetics between the head and the body. People have said: »Get out of your head and back into the body «. I think that the body is in the mind and will give you some research supporting this concept. The new techniques for studying the brain provide increased information about its structure and function. With the introduction of brain imaging techniques and pet scans, somatic states have been correlated with not only physical parts of the brain, but the mind has been reintroduced as an energetic system. No longer are we a mind vs. a body, but the mind and the body are one, functioning as an intricately related system transferring information regarding somatic states and processing verbal and cognitive events. Our somatosensory experiences are represented in our mind. We are born with a complete representation of our body in our brain. How do I know this? Well, let me tell you. This is really interesting research - almost as good as the >Big O<. Researchers at McGill University in Canada found that people born without arms and legs still feel those body parts (Melzack et al. 1997, pp. 1603-20). This means that people feel arms and legs even though they are missing at birth. The researchers 
conclude that the brain needs to have information about what is going to happen. It anticipates that it will be getting information from a body that has two arms and legs, and that there will be a mother with two breasts as sources of food. »The body we perceive is in large part built into our brain - it's not entirely learned «.

Our body/mind anticipates stimulation from the caretaker. It has already formed a somatosensory neural network developed to receive stimulation. That stimulation builds structure and forms our somatosensory memories. This somatosensory structure is what psychoanalysts call the unconscious. Because of this neurobiological research, analysts are now becoming aware of the importance of somatic interventions. Bioenergetic therapists have for years worked with techniques that influence these structures.

Researchers studying the mind have found that traumatic events are stored in a part of the brain called the cingulate gyrus. Traumatic experiences overwhelm the system and they remain stored in the cingulate gyrus not as memories, but as highly affective events never fully processed and organized by the system. They are stored as somatosensory experiences and feelings. This structure, the cingulate gyrus stores these highly arousing stimulating events until they can be organized by the cerebral cortex into a coherent verbal description of the event. Another part of the brain, the thalamus acts as a door between the cingulate gyrus and the cerebral cortex. The thalamus pulses at about 40 beats / minute. When the organism is in a state of trauma, somatosensory information floods the system. The thalamus is presented with more stimuli than the cerebral cortex is able to organize, so the material is routed back to the cingulate gyrus.

Trauma time is always present time. Character is now. That's why we can't » just get over it «. Organizing information about our character, information we gather through body readings and by feeling the experience in our bodies needs to be gathered in measured doses in order for this material to be passed through the thalamus and organized by the cerebral cortex. Thus, the therapeutic window is the optimal level of arousal for moving the material through. It is the amount of highly affective activating material that can be processed by a person without them flooding, dissociating or freezing. Then, the material can be transferred to the cerebral cortex where it is organized into a coherent life story; a narrative about what happened in the past, not an ongoing traumatic experience. 
Let me give you an example. A young man in one of the first year training groups would report that everything was fine. When asked to elaborate by the other trainees, he became defensive and angry, saying that he had already told them how he felt. One day, I noticed that he flinched when one of the male trainers walked by. I told him what I had seen and he seemed curious about the behavior. I pointed out how his body stiffened and pulled back, almost like the beginning of the Babinsky startle reflex. I also told him I had noticed that he only reacted this way when men walked by, looming over him. When I said the words, »looming over him ", his face blanched and his eyes looked vacant. When one of the trainees asked him how he felt, he didn't answer but remained in what trauma therapists call `frozen immobility`, he couldn't fight or flee. Because he was already flooded, I wanted to give him time to come into the room and protect him from more input. I told him that he was safe and that he didn't have to do or say anything. I would wait for him. The vacant look in his eyes cleared. I invited him to find the parts of his body he could feel. After finding his legs and recognizing the desire to flee, he said, » My father beat me«. Again, his body stiffened and his eyes began to have a glassy appearance. I brought his attention back to the room and then slowly invited him back into his body, modulating and titrating how much he was beginning to reexperience.

He had a good therapist and by the end of the fourth year of training, he was able to talk about the physical and verbal abuse he received from his father without flooding. It was past abuse, not happening anymore. The events now exist as a coherent narrative, as memories that are stored in the cerebral cortex. He is less often flooded by body feelings of fear and shame.

Although important and necessary for healing, these psychotherapeutic issues are still within the first and second paradigm. These are processes occurring within the client, which are separate from what is being created by the therapist and client together, the third paradigm. When the relationship is included in the therapeutic analysis, the ability to influence these processes is augmented.

Let us take a look at Lowen's own biographical narrative of his therapy with Reich. The following is a description in Lowen's own words taken from the book, Bioenergetics. 
"Following the experience of fear when I saw my mother's face, I went through a long stretch of several months during which I made no progress. I was seeing Reich three times a week then, but I was blocked because I couldn't tell Reich my feelings about him. I wanted him to take a fatherly interest in me, not merely a therapeutic one, but knowing this was an unreasonable request, I couldn't express it. Struggling inwardly with the problem, I got nowhere. Reich seemed unaware of my conflict. Try as hard as I could to let my breathing become deeper and fuller, it just didn't work.

I had been in therapy about a year when this impasse developed «.

Lowen says he was able to discharge a great amount of fear and then he hit a plateau, unable to deepen his breathing or report feelings. Now I want you to think about what you might do if you had a client in the same situation. Turn to your neighbor and talk about what intervention you might use (3 minutes).

This is what Reich did.

»Reich suggested I quit. »Lowen «, he said, " you are unable to give in to your feelings. Why don't you give up «? His words were a sentence of doom. To give up meant the failure of all my dreams. I broke down and cried deeply. It was the first time I had sobbed since I was child. I could no longer hold back my feelings. I told Reich what I wanted from him, and he listened sympathetical$1 \mathrm{y}$ (Lowen 1975, p. 21).

This is the defining moment in Lowen's therapy. He goes on to say, that shortly after the breakdown in the therapy, Reich took a vacation. When he returned, Reich suggested that they take a break from therapy for a year. Perhaps, Lowen was hurt, when Reich left him. I wonder what Bioenergetics would have looked like as a therapy system if Reich had treated Lowen the way you would have treated your client?

Several years ago at Arles, Leslie Case gave a talk outlining the number of ways her therapists had injured her. I was sitting with my husband, a physician, during this talk. At first he looked at me and said, "She's talking here about a certain type of clients ". I said nothing but put my arm on top of his. Next he whispered rather harshly: »Well you've done that too «, 
referring to the number of ways Leslie had been dismissed or accused. »Of course «, I whispered back. Finally, he held his head in his hands and said, »I've hurt so many people«. I answered: »We all have«.

In the past we have been hurt in Bioenergetics and have hurt others. And unless we are willing to learn from our mistakes, we will continue to do harm and be harmed in the same ways. Lowen at one point said that he felt that Bioenergetics didn't work because people were sicker than he believed. That statement has a ring of truth to it. The belief at that time was that if the armor was removed, then the true authentic healthy self would be revealed. The problem is that armor describes the outside of the person, it is the muscular holdings one builds to defend against feelings and needs that weren't met when we were young. Armor is a surface structure.

The second paradigm shifted the focus from only looking at the outside holding patterns to inside the person. This second shift produced great contributions to the field of Bioenergetics - Stanley Keleman's classic work Emotional Anatomy (1985) and the work in Bodynamics on the internal tube and viscera. The findings from neurobiology and Peter Levine's work on how the brain processes trauma are all part of the second paradigm. Levine's research focusing on the brain and mind is confirming the necessity of working with non-verbal states. But how should we work with these states? If we become too enamored of the inside of the body as we have been by the outside, we will continue to harm and be harmed by our psychotherapeutic interventions.

Now that it is time for another paradigm shift, what should be the nature of this shift? Fortunately the field of somatic psychotherapy is finally producing some good researchers who are beginning to ask the question: »Does Bioenergetic therapy heal and how «? Christa Ventling (2002) conducted a terrific research study for which she won an award from The USA Body Psychotherapy Association. The good news is that her research validated the effectiveness of Bioenergetic Analysis. ${ }^{1}$

1 This replicates the results from Gudat (1997). Koemeda-Lutz et al. (2003) report preliminary positive results from a prospective study evaluating the effectiveness of body psychotherapies. 
However, Ventling also discusses the following result:

"Although we assumed that our patients would be ascribing a high efficacy to body work with regard to gaining new insights, we were disappointed in the answer, as only $56 \%$ did so. Even fewer $(46 \%)$ felt that bodywork was the cause of their improved quality of life. Clearly the exact variables that are causing the overall very positive changes in BAT (Bioenergetic Analysis) cannot be pinpointed at this time. The theory that it is mainly the bodywork needs further investigation. We assume that the quality of the relationship between patient and therapist plays a major role and plan to study it further « (Ventling 2002, p. 21).

Let me repeat, only a little more than half of the clients reported that the body work caused them to heal and less than half reported it improved their quality of life. This is the same finding that Pamela Bell reported to us earlier in the conference when researching the effect of Bioenergetic therapy on brain wave activity. She found that while there was a small effect on brain wave activity from participating in Bioenergetic exercise classes, a masochistic patient showed a significant amount of change after a particularly expressive therapy session. Christa Ventling in her article suggests that the healing occurred in the relationship. But what part of that relationship? In the same journal Douglas Radandt (2002) tried to investigate a possible relationship between a therapist's body awareness and the strength of the therapeutic alliance. Randant found although there was a positive correlation between the therapist's awareness of his own body sensations and movements and the therapeutic alliance, it did not reach statistical significance. If the body work by the patient and the therapist's awareness of his own body are only contributing a small portion to the therapeutic outcome, what is causing therapeutic change in Bioenergetics? Parish and Eagle in the recent journal of Psychoanalytic Psychology (2003) say: »There seems to be an increasing consensus that therapeutic change is based not only on cognitive factors such as awareness and insight «. For psychoanalysts, awareness and insight have been the focus while for Bioenergetic Analysts, bodily awareness, physical expression as well as cognitive factors and insights have been the focus. So what is causing the change? The writers suggest that change occurs because of the 
nature of the relationship between patient and therapist. And again, the question is: what part of the relationship?

There has been wide recognition that patients in psychotherapy often experience strong feelings toward their therapists, transference. One useful way of understanding the therapeutic relationship, when it works well is that the therapist, at least in certain respects, as David Campbell and Bob Hilton have been telling us for years serves, as an attachment figure, as a ssecure base from which the patient can explore his or her inner world. Remember, Lowen was longing for Reich to be a secure loving father, who would be interested in him. Thus, the missing elements of our study of body awareness or bodywork interventions are: empathy, attunement, and congruence. Because the therapist is aware of his own body sensations does not mean that he is attuned to what is happening within the client's body. In other words, I suspect that it is the therapist's awareness of what the client needs in terms of an attachment figure, including somatic and bodily interventions. Our ability to be empathic and attuned to the client is what is healing in the relationship.

Let me give you an example of body attunement. It is from the book Seabiscuit, the name of the most famous racehorse in American history. The story is really about the relationship between the horse, his trainer, and his jockey. Seabiscuit is about to race against War Admiral. The country has been waiting several years for this match to occur. Even President Roosevelt is listening on the radio and won't let his advisors enter the room until the race is finished. Seabiscuit is a short stocky less favored horse. They are approaching the track to begin the race.

"War Admiral walked up the track first, twirling and bobbing. Blunt-bodied Seabiscuit plodded along behind, head down. He looked up once, scanned the crowd, then lowered his head again« (Hillenbrand 2002, p. 268).

Let's pause a minute here. Ask yourself: What do you think Seabiscuit is feeling?

Here is what people at the time who actually saw Seabiscuit thought he was feeling.

»One witness compared him to a milk-truck horse. Shirley Povich of the Washington Post thought he exhibited ‘complete and colossal indifference« 
This is what his jockey says about him.

»The appearance was deceiving. Woolf could feel it. In post parades he was accustomed to the smooth levelness of Seabiscuit's walk, the gentle gait of a horse who puts his hooves down carefully. But this day Woolf felt something new, a gathering beneath him, something springlike. The horse was coiling up«.

Woolf was sensing something happening inside the horse that a person reading the horse's body language from outside can't know. He was exploring his 'felt sense‘, and it was different from what he saw when drawing conclusions from observations about the horse's external body language.

The current research utilizing brain imaging is finding that this somatic empathic attunement appears to be necessary for developing attachment in infants and for any therapy process. This research, which has been summarized by Alan Schore and others points to the importance of the right brain in attachment, trauma, and integrating emotional experiences. They have found that what is healing in psychotherapy is the relationship, and much of what transpires between the therapist and client is transmitted to the occipital cortex and is unconscious both to the client and the therapist. This part of the brain develops between the ages of one to three years of age, again (schizoid to rigid), but most dramatically in the first few months. This means that the memories stored there are nonverbal and comprise implicit memory, the same kind of memory that is used for such functions like riding a bicycle or knitting. These are body memories. We don't have a verbal description of the steps needed each time we get on a bicycle or knit. Even if we haven't ridden a bike or picked up knitting or crochet needles for years, we still remember how to do it.

An experience from my own life illustrates how these memories function. I'm quoting from my article in the recent IIBA journal on research.

"I had the privilege of having my baby at home, so the morning after Myrrhia's birth I turned on the radio while she nursed. Music passionately delivered by a gospel choir mirrored the joy I felt for having such a beautiful being in my arms and I began dancing. Previous to her birth, I had never listened much to gospel music and had certainly never danced to it. I found myself moving to this music during the first three years of her babyhood and even purchased a couple of albums. 
Many years later, when Myrrhia was 8-years-old, she and I were having tea with my Aunt Barbara. My aunt told me that the black woman, Helen Bell who helped care for me the first four years of my life was the lead person in the gospel church. Every Sunday she would dance down the aisles leading her congregation. She loved gospel music and must have danced, holding the baby Helen (me) in her arms. So, although I didn't know that Helen Bell went to church or danced, my body had stored memories of that experience. Holding my baby released memories of my own infancy, which until Aunt Barbara had told me about, I didn't know had been my experience.

These early attachment experiences are stored in our limbic brain as a prototype for relationships" (Resneck-Sannes 2002, pp. 113-114).

We aren't able to retrieve these memories by our usual method of verbal or even visual recall. They are stored as somatic impressions drawing us to certain relationships. A certain behavior emerged, dancing to gospel music triggered by the birth of my daughter. Dancing is a somatosensory behavior which mirrored an experience from my infancy of which I have no conscious memory.

So that explains implicit memory, but I'm discussing something beyond memory. I'm talking about a communication between two minds, an empathic attunement. Here is another example straight from the Bioenergetic mat. At lunch one day I was discussing with a colleague of mine, Tom, the importance of understanding the difference between placing a hand under or on top of the hand or foot of a client. He described a situation while working with a man on the mat. The man had placed his hand on his chest, and Tom placed his hand over his client's hand. Tom then had the sense that he needed to place his hand on the man's chest and have the man place his hand on top of his. We discussed the differences between the two interventions: support vs. being trapped, being held vs. being held down, but the key here is that Tom's mind/body knew what was the right thing to do.

When the therapist is in resonance with his client, then he can present material that stimulates or soothes. By titrating the amount of material presented the therapist prevents the client from being over-whelmed, dysregulated and at worst re-traumatized. An empathic therapist is neither 
understimulating (too removed, neutral, not there), nor over-stimulating (not modulating the material) to prevent the client from flooding, dissociating or splitting off. When our clients are over-charged and over-stimulated, we need to calm and contain our own energy. The therapist needs to be attuned such that the material is within the therapeutic window, enabling it to be passed through the thalamus to the cerebral cortex.

Our body interventions should become an invitation for the client to explore somatically (sensate) feelings, meanings, imagistic representations, and internal object representations. We then become the mirroring, empathic, attuned other that hopefully will begin to live inside our client's body/mind and support them in being who they are: vulnerable, needy, scared, loving, hard, angry, punishing, resentful, sadistic, victim, little child who wants to be rescued.

One of the important aspects of teaching character analysis is to train Bioenergetic therapists in this kind of body empathy. A reading of the body should lead to a greater understanding of the client's issues, not only intellectually but to trigger an empathic response and adjustment in our own bodies. The neurobiological research, the psychoanalytic journals, the emotionally focused therapy articles, they are all talking about the importance of somatic attunement for processing emotionally laden material. Yet, none of this literature is mentioning the word Bioenergetics or referring to our arsenal of techniques and interventions. We can titrate, modulate in a way that other analytic and cognitive behavioral therapists are unable. Our knowledge of breath, of grounding, of ways to form somatic and energetic boundaries, and our knowledge of affect containment enables us to be sensitive to flooding. When I have clients who are over-charged or suffering from chronic illnesses resulting from an over-reactive immune system, like fibromyalgia or chronic fatigue, my physical contact is different from when I am trying to open a block. In both cases my touch is firm. However, when clients are highly activated, I try to maintain a state of grounded stillness. I slowly and gently make contact, waiting for my hand to feel their pulsation. This is different from when I am opening a block. Then, I ground by allowing my own breath to deepen and my charge to build. I contact the body part that needs to release, waiting for the area of holding to soften, inviting me in deeper, as deep as the body allows. None of this is 
new to you. We learn about different kinds of touch and contact the first year of training.

I recently experienced a painful bout of sciatica. When the nerves of my back were inflamed, I sadly experienced how few body workers are aware of attuned contact. Before this bout of sciatica, I used to ask people to stand on my back, including Jim Miller (all three hundred pounds of him). When the nerves of my spine were inflamed, I needed a gentle touch. I couldn't get a massage therapist to understand how to touch me without putting charge into my body.

I meet with a group of therapists twice a year to work on ourselves. Before our meeting I had a fantasy of being gently held. Without me needing to ask, Virginia Hilton offered to hold me. Her touch was sensitive and present, yet not activating, invasive or demanding. Bioenergetic Analysts have these skills and no one knows. There have been few books written and until recently, very little research. What a shame.

Finally, one more change needs to occur in the practice of Bioenergetic Analysis. As I mentioned before, the concept has been that the body is the access to the unconscious. By enabling clients to be aware of their somatic holding patterns, the energy will flow freely through the body in a harmonic wave. This has been the thinking of all the somatic therapies so far. As I mentioned before, it is a non-relational theory. The research has been showing for years that clients report that neither insight nor body interventions heal by themselves. I think the body interventions are necessary but not sufficient for healing. I'm not saying that our somatic interventions should be discarded. Quite the contrary, they must occur in the context of an attuned, empathic relationship. This means that the therapist must no longer be separate from the client, but now must enter the room as a human being.

For instance, let's address the issue of anger. When clients hit the cube, it is a means for them to recognize the holding patterns of anger in their body and to identify with the emotion and the body sensations. The goal of hitting is not to "get rid of feelings " as so often has been the confusion of therapists; nor is it a way of dealing with resistance in the therapy. Hitting the cube is to enable the client to connect with the feeling of anger and the muscles used to either hold back or express it. 
However, when we have injured a client and they are angry with us, we don't only direct them to hit a cube. We are the ones who need to be able to say, »I'm sorry « and repair the damage we inadvertently or necessarily caused. Of course, we don't want to hurt people, but we do. It is the reparation of these moments of therapeutic disruption that lead to healing. Ruptures and repair are part of the therapy process. A character analysis, a true relational therapy recognizes that the therapist has to be present for all of the client's feelings - love, anger, rage, sexuality, and resistance. Hitting is important for a client to recognize anger, the holding in the back and the arms. But a cube can't say »I'm sorry«. We need to say »I'm sorry«.

Let me give you an example from my own practice. A woman I have been seeing for several years entered my office on the verge of tears. She is a sophisticated psychotherapist, has good analytic skills which she uses defensively to hide her hurt and vulnerability. Although she wasn't directly accusing me, she was telling me that I hadn't stayed focused on her vulnerable issues. She went on to say that the night before, while talking to her partner, she became so frustrated that her attempt to push the cat off of the bed became a kick. Although she was surprised and shocked by her aggression, the client was more upset that her partner didn't remain interested in her feelings; and instead wanted to process her shock about the physical aggression used on the cat. She then told me of all the ways she could not be comforted, didn't believe people's empathy. She continued saying that in our therapy she had avoided these painful feelings which allowed her to be vulnerable by analyzing others. I had a fantasy of offering her my hand to hold, which I was aware she would probably reject. However, I felt that it was important that I make the offer. As I expected, she told me that it wasn't enough. She then asked why she felt bad and couldn't accept my offer. Once again, she was avoiding difficult feelings by analyzing her needs and motives. Although in the past I had colluded with her in avoiding these issues, this time I answered: "I'm sorry for disrupting your expression by offering my hand. I'm also sorry for in the past when I explored your needing to ask why. But this time, I don't care why. I just want to be here with you. I don't even care if I do it right, I just want to be here with you «. She started to cry and then began analyzing her body sensations, why her partner couldn't give that response. I stopped her and just said, »I'm sorry that I let you avoid these feelings in the past, 
but I am with you now «. She began to sob deeply. I felt that I was saying »I'm sorry « for the missed opportunities to comfort her and for all of the people who missed comforting her. It was more important to repair those missed moments than to have the >correct somatic intervention

Now I will talk about the future by asking: What is our standing in the therapeutic community now and what is possible for us? First, do you know what is considered the cutting edge of psychotherapeutic practice today? Cognitive Behavioral therapy. Why? Because they have research studies validating the efficacy of their approach. Investigators from the University of Northern Iowa surveyed 425 clinical psychologists, and 254 of them reported having experienced depression. Although $53 \%$ of the depressed therapists said they employ primarily cognitive-behavioral methods in their practices, $40 \%$ chose psychodynamic therapy for their own treatment. The second most popular modality they sought was Gestalt (19\%). Only 12\% sought cognitive behavioral therapy. So while insurance companies in the U.S. tend to reimburse for cognitive behavioral interventions, that is not the modality that clinicians are choosing for themselves when they need help (Parish \& Eagle 2003).

Why aren't they choosing Bioenergetics? It's not even mentioned as a possible choice of intervention. Like psychoanalysis and cognitive behavioral therapy, we need to develop a literary tradition espousing the interventions that are specific to Bioenergetic Analysis. We need to concentrate on those interventions that heal and try to localize the ingredients, both active and passive that contribute to therapeutic change. I would like you for a moment to consider the following remarks that were made during a panel discussion at the 2002 meeting of the psychoanalytic society. (Kirsner, D. 2001) Present on the panel were some of the most well known analysts of our time. Douglas Kirsner began with a highly critical view of the sunwarranted claims to knowledge made by analysts in the absence of scientific support. Otto Kernberg urged the development of clear standards for training. The need to develop research skills as a part of training he called an ressential task . Robert Wallerstein discussed the organizational structure of institutes and their curricula. Feeling that psychoanalysis must avail itself of developments in allied fields, such as cognitive sciences, he supported the move of institutes into academic settings in order to surviver. 
We, Bioenergetic Analysts are also faced with the knowledge that if we wish to become members of the larger therapeutic community, then we must gear our research and theory to what is considered the cutting edge of practice today. In so doing, do we lose what is essential to a Bioenergetic practice? Or, by joining with the larger community are we incorporating effective therapeutic techniques, enhancing our knowledge base and becoming a major force in the community at large? If we don't join, I'm afraid that we are in danger of becoming an esoteric therapeutic community that dissolves into the mists like Avalon and King Arthur's knights of the round table, an idealized memory in the minds of a select few.

This time in history is an especially fortuitous one for somatic psychotherapies. We have been aware that trauma is stored in the body. Developmental trauma is stored there. In fact, all of the latest research points to a body psychotherapy. Schore proposes that 'primitive mental states are more precisely characterized as >psychobiological states $<$ The field of psychotherapy is acknowledging that the focus of therapy must shift from cognitions, images, and dreams to include non-verbal somatic states. Bioenergetic Analysts are attuned to these states and deep somatic experiences. The time is now for us to join with other analytic and trauma therapists, not only to learn what they have to offer but to inform and to teach them that we know how to regulate somatic states. We should be writing articles for other journals, like The USA Body Psychotherapy Journal as well as for traditional psychoanalytic and academic journals. We need to be teaching in academic settings and providing support for students engaging in research. It is imperative that we join with and support other therapy organizations both where we live and in the larger psychotherapy community. We can be informative and even teach them a few things by sharing our ideas, letting them know that we have interventions and theories that are helpful to and consistent with the way they are doing therapy. Lowen was our spokesperson, writing books and demonstrating Bioenergetic practice at large conferences. He has retired and we need to step forward and take his place. We have a great deal to offer to the psychotherapeutic community and now is the time. 


\section{References}

Brockman, R. (1998): A map of the mind: Toward a science of Psychotherapy, Madison, Ct. (Psychosocial Press).

Brockman, R.. (2001): Toward a Neurobiology of the Unconscious. Journal of the American Academy of Psychoanalysis and Dynamic Psychiatry 29(4), 601-615.

Gudat, U. (1997): Bioenergetische Analyse als ambulante Psychotherapie Anwendungsbereiche und Wirkungen. Psychotherapie Forum 5, 28-37.

Hillenbrand, L. (2002): Seabuiscuit - An American Legend. New York (The Ballantine Publishing Group).

Keleman, S. (1985): Emotional Anatomy. Berkeley, California (Center Press).

Kirsner, D. (2001): The Future of Psychoanalytic Institutes - A Dialogue. Psychoanalytic Psychologist, 18(2),195-212.

Klopstech. A. (2002): Modelle therapeutischen Handelns: Der psychoanalytische und der bioenergetische Weg. In: Koemeda-Lutz, M. (Hg.) Körperpsychotherapie - Bioenergetische Konzepte im Wandel. Basel (Schwabe Verlag). Engl.: The Bioenergetic Use of a Psychoanalytic Conception of Cure. Bioenergetic Analysis. The Clinical Journal of the International Institute for Bioenergetic Analysis, 11 (1) 55-66.

Koemeda-Lutz M., Kaschke M., Revenstorf D., Scherrmann T., Weiss, H. \& Soeder U. (2003): Zwischenergebnisse zur Wirksamkeit von ambulanten Körperpsychotheapien. Eine Multicenter-Studie in Deutschland und der Schweiz. Psychotherapie Forum 11 (2) 70-79.

Engl.: Preliminary Results Concerning the Effectiveness of Body-Psychotherapies in Outpatient Settings - A Multi-Center Study in Germany and Switzerland (www.eabp.org).

Lowen, A. (1958): The Language of the Body. New York (Collier Books).

Lowen, A. (1975): Bioenergetics. New York (Penguin Books).

Lowen, A. (1983): Narcissism. New York (Macmillan Publishing Co.).

Melzack, I., Lacroix, R. \& Schultz,G. (1997): Phantom limbs in people with congenital limb deficiency or amputation in early childhood. Brain 120, 1603-20.

Parish, M. \& Eagle, M. (2003): Attachment to the therapist. Psychoanalytic Psychology 20 (2) 271-286.

Radandt, D. (2002): Therapist's Body Awareness and Strength of the Therapeutic Alliance. The USA Body Psychotherapy Journal, 52-62. 
Schore, A.N. (1997): A century after Freud's Project: Is a rapprochement between psychoanalysis and neurobiology at hand? Journal of the American Psychoanalytic Association, 45, 841-867.

Siegel, D.J. (1999): The developing mind: Toward a neurobiology of interpersonal experience. New York (Guilford Press).

Stark, M. (1999): Modes of Therapeutic Action. Northvale N.J. (Jason Aronson). Ventling, C. (2002): Efficacy of Bioenergetic Therapies and Stability of the Therapeutic Result: A Retrospective Investigation. The USA Body. Psychotherapy Journal, 5-27.

Helen Resneck-Sannes, Ph.D., 216 Suburbia Avenue, Santa Cruz, CA, 95062, USA, E-mail: HelenRS@aol.com 